\title{
Cannabidiol Reverses MK-80I-Induced Disruption of Prepulse Inhibition in Mice
}

\author{
Leonora E Long*,', Daniel T Malone' and David A Taylor' \\ 'Department of Pharmaceutical Biology and Pharmacology, Victorian College of Pharmacy, Monash University, Victoria, Australia
}

\begin{abstract}
Cannabidiol, a nonpsychoactive constituent of the Cannabis sativa plant, has been reported to act as an agonist of the vanilloid I channel in the transient receptor potential family (TRPVI) and also to inhibit the hydrolysis and cellular uptake of the endogenous cannabinoid anandamide. Cannabidiol has also been reported to have potential as an antipsychotic. We investigated the effect of cannabidiol on sensorimotor gating deficits in mice induced by the noncompetitive NMDA receptor antagonist, MK-80I. Sensorimotor gating is deficient in psychotic disorders such as schizophrenia and may be reliably measured by prepulse inhibition (PPI) of the startle response in rodents and humans. MK-80I (0.3-I mg/kg i.p.) dose dependently disrupted PPI while cannabidiol ( $1-15 \mathrm{mg} / \mathrm{kg}$ i.p.), when administered with vehicle, had no effect on PPI. Cannabidiol (5 mg/kg i.p.) successfully reversed disruptions in PPI induced by MK-80 I (I mg/kg i.p.), as did the atypical antipsychotic clozapine ( $4 \mathrm{mg} / \mathrm{kg}$ i.p.). Pretreatment with capsazepine ( $20 \mathrm{mg} / \mathrm{kg}$ i.p.) prevented the reversal of $\mathrm{MK}-80 \mathrm{I}-$ induced disruption of PPI by cannabidiol, providing preliminary evidence that TRPVI receptors are involved in the reversal of MK-80 Iinduced sensorimotor gating deficits by cannabidiol.

Neuropsychopharmacology (2006) 3 I, 795-803. doi:I 0. I038/sj.npp. I 300838; published online 27 July 2005
\end{abstract}

Keywords: cannabidiol; capsazepine; endocannabinoid; schizophrenia; sensorimotor gating; vanilloid receptor

\section{INTRODUCTION}

Cannabidiol is a nonpsychoactive constituent of the Cannabis sativa plant. The major psychoactive Cannabis constituent $\Delta^{9}$-tetrahydrocannabinol $\left(\Delta^{9}\right.$-THC) activates at least two cannabinoid receptors, $\mathrm{CB}_{1}$ and $\mathrm{CB}_{2}$, which are coupled to G-proteins (Howlett et al, 2002). Unlike $\Delta^{9}$-THC, cannabidiol has very weak affinity for $\mathrm{CB}_{1}$ and $\mathrm{CB}_{2}$ receptors (Bisogno et al, 2001) and does not alter neural uptake of amine neurotransmitters such as dopamine and 5-HT (Hershkowitz and Szechtman, 1979) or excite dopaminergic nerve cell firing (French et al, 1997). Cannabidiol acts as a full agonist in vitro at the transient receptor potential vanilloid receptor (TRPV1), with desensitization and maximal stimulation similar to the prototypical TRPV1 agonist capsaicin (Bisogno et al, 2001). Cannabidiol produces anti-inflammatory activity in rats mediated by TRPV1 but not by $\mathrm{CB}_{1}$ or $\mathrm{CB}_{2}$ receptors (Costa et al, 2004), although it has been reported that it does not elicit the decrease in blood pressure or increased respiration usually produced by TRPV1 activation by capsaicin or by

\footnotetext{
*Correspondence: LE Long, Department of Pharmaceutical Biology and Pharmacology, Victorian College of Pharmacy, Monash University, 38I Royal Parade, Parkville, Victoria 3052, Australia, Tel: +6I 39903 9085, Fax: + 6139903 9638, E-mail: leonora.long@vcp.monash.edu.au Received 7 January 2005; revised 23 May 2005; accepted 7 June 2005 Online publication: 21 June 2005 at http://www.acnp.org/citations/ Npp062 1050500 I I/default.pdf
}

the endocannabinoid anandamide (McQueen et al, 2004). Cannabidiol inhibits the hydrolysis of anandamide in mouse brain microsomes (Watanabe et al, 1996; Bisogno et al, 2001) and the carrier-mediated cellular uptake of anandamide in mast cells (Rakhshan et al, 2000; Bisogno et al, 2001). This suggests that administration of cannabidiol may enhance the activity of endogenous anandamide, although the $(+)$-stereoisomer and other cannabidiol analogues display more potent inhibition of anandamide inactivation than the natural isomer, (-)-cannabidiol, used in most pharmacological investigations (Bisogno et al, 2001).

Following the observation that cannabidiol reversed effects of $\Delta^{9}$-THC in humans, such as anxiety (Karniol et al, 1974; Zuardi et al, 1982), research also examined its potential as an antipsychotic. Cannabidiol was reported to reverse some dopaminergic effects associated with apomorphine, such as stereotypy, prolactin secretion, and palpebral ptosis, while producing none of the catalepsy associated with 'typical' antipsychotics such as haloperidol (Zuardi et al, 1991). This group later showed that cannabidiol increased Fos protein expression in the nucleus accumbens, but not in the striatum, indicating that cannabidiol produces neuronal activation in mesolimbic areas but not in motor control areas, and thus reinforcing the potential of cannabidiol to produce few unwanted motor effects (Guimaraes et al, 2004). In humans, cannabidiol has been shown to reverse binocular depth inversion (a model of 
impaired visual perception during psychotic states) produced by the synthetic psychotropic cannabinoid nabilone (Leweke et al, 2000). Cannabidiol was also efficacious in reducing psychotic symptoms and well tolerated in a clinical trial in a young schizophrenic female patient (Zuardi et al, 1995). Most recently, cannabidiol was reported to reverse hyperlocomotion produced by amphetamine and ketamine in mice without producing catalepsy (Moreira and Guimaraes, 2005).

Prepulse inhibition (PPI) is an animal model of sensorimotor gating, and is defined as the decrease in the acoustic startle response when a nonstartling prepulse is presented $30-500 \mathrm{~ms}$ before the startling pulse (Hoffman and Ison, 1980). Sensorimotor gating is deficient in patients with psychotic disorders such as schizophrenia (Braff and Geyer, 1990). Pharmacological models of disrupted PPI include dopaminergic and serotonergic activation and NMDA receptor antagonism and are excellent predictors of antipsychotic activity (Geyer et al, 2001). Another form of startle response plasticity is habituation or the progressive reduction in response to an initially novel stimulus when the stimulus is presented repeatedly to a subject. The rate of habituation can be manipulated and is also reduced in psychotic disorders (Geyer et al, 1990; Bolino et al, 1992). Based on observations in the literature of the antipsychotic potential of cannabidiol, the aim of the following experiments was to test the ability of cannabidiol to reverse disruptions in PPI induced by the noncompetitive NMDA receptor antagonist MK-801 and to determine the involvement of TRPV1 receptors in the effects of cannabidiol using the TRPV1 antagonist capsazepine. Clozapine was administered as a positive control to test the effects of a known antipsychotic against those of cannabidiol in reversing MK801-induced disruptions.

\section{METHODS}

\section{Animals and Housing}

Male Swiss mice weighing between 25 and $30 \mathrm{~g}$ were used. The animals were housed in group cages and kept at $22^{\circ} \mathrm{C}$ with a $12 \mathrm{~h}$ light-dark cycle. Food and drinking water were available ad libitum. The animal experimental protocols were approved by the Victorian College of Pharmacy, Monash University Animal Ethics Committee and conform to the guidelines set out by the National Health and Medical Research Council and all Australian Government regulations.

\section{Drug Treatment}

As a result of the number of interactions to be investigated, the injection schedule consisted of three injections. All animals were exposed to one treatment combination only.

Experiment 1: $M K-801$. Separate groups of mice were injected intraperitoneally (i.p.) with vehicle $(1: 1: 98$ Tween ${ }^{\circledR} 80: \mathrm{EtOH}$ : saline, VEH1) followed $20 \mathrm{~min}$ later by a second i.p. injection of vehicle $\left(1: 1: 18\right.$ Cremophor $^{\mathrm{R}}$ EL: EtOH : saline, VEH2). Then, $20 \mathrm{~min}$ after this, mice were given a third i.p. injection of MK-801 $(0.1,0.3$, or $1 \mathrm{mg} / \mathrm{kg}, \mathrm{MK})$.
Experiment 2: Cannabidiol. Separate groups of mice were injected i.p. with vehicle (VEH1) followed 20 min later by an i.p. injection of cannabidiol $(1,5$, or $15 \mathrm{mg} / \mathrm{kg}, \mathrm{CBD})$ and then followed $20 \mathrm{~min}$ later by a third i.p. injection of vehicle (0.1\% ascorbic acid in distilled water, VEH3).

Experiment 3: Capsazepine + cannabidiol $+M K-801$. Separate groups of mice were injected i.p. with capsazepine $(20 \mathrm{mg} / \mathrm{kg}, \mathrm{CPSZ})$ or vehicle (VEH1), followed $20 \mathrm{~min}$ later by i.p. cannabidiol $(5 \mathrm{mg} / \mathrm{kg}, \mathrm{CBD})$ or vehicle (VEH2) and then followed by a third injection 20 min later of i.p. MK$801(1 \mathrm{mg} / \mathrm{kg})$ or vehicle (VEH3).

Experiment 4: Clozapine $+M K-801$. Separate groups of mice were injected i.p. with vehicle (VEH1) followed $20 \mathrm{~min}$ later by an i.p. injection of clozapine $(4 \mathrm{mg} / \mathrm{kg}, \mathrm{CLOZ})$ and then followed $20 \mathrm{~min}$ later by a third i.p. injection of MK$801(1 \mathrm{mg} / \mathrm{kg})$ or vehicle (VEH3).

This regime of three injections ensured that all mice received the same number of injections. Thus the data from groups receiving VEH1 + VEH2 + VEH3, VEH1 + CBD $5+$ $\mathrm{VEH} 3, \mathrm{VEH} 1+\mathrm{VEH} 2+\mathrm{MK} 1$, and VEH1 + CBD $5+\mathrm{MK} 1$ were reused in several analyses, as the appropriate vehicle control treatments were present.

\section{Behavioural Testing}

Startle reactivity was measured using two SR-LAB startle chambers (San Diego Instruments, San Diego, CA). The animal enclosures consisted of a perspex cylinder $40 \mathrm{~mm}$ in diameter on a platform connected to a piezoelectric accelerometer that detected movement within the cylinder. Above the cylinder was a speaker capable of producing white noise up to $120 \mathrm{~dB}(\mathrm{~A})$ attached to programmable audio controls. The animal enclosure was located in an illuminated, ventilated, and sound-attenuated chamber.

All testing took place during the light phase. Animals were acclimatized in the startle chambers during three $0.5 \mathrm{~h}$ sessions: a morning and afternoon session on the day before testing and a morning session on the test day. In the afternoon of the test day, mice received three injections as described above. At $5 \mathrm{~min}$ after the third injection, mice were placed in the startle chamber. Mice were returned to their home cage between injections and before placement in the startle chamber.

After $5 \mathrm{~min}$ acclimatization to the background noise in the startle chamber of $70 \mathrm{~dB}(\mathrm{~A})$, startle stimulus trials of $120 \mathrm{~dB}(\mathrm{~A})$ intensity and $40 \mathrm{~ms}$ duration were applied, either alone or preceded by $100 \mathrm{~ms}$ with a prepulse of an intensity of 3,6 , or $12 \mathrm{~dB}(\mathrm{~A})$ above background and $20 \mathrm{~ms}$ duration. Prepulse alone trials of 3,6 , or $12 \mathrm{~dB}(\mathrm{~A})$ above background were also presented, as were trials containing no stimulus at all. A total of 10 trials of each type were presented in a pseudorandom order, with the intertrial interval varying in a random fashion from 8 to $22 \mathrm{~s}$. An extra 10 pulse alone trials were presented in blocks at the beginning and end of each test session in order to observe habituation of the startle response and to scale down the initial startle response to a stable plateau. The whole body flinch (movement) elicited by the startle stimulus was detected by the accelerometer. PPI was calculated as a percentage of 
this startle response using the formula: \% PPI $=(1-$ (startle amplitude after prepulse-pulse pair/startle amplitude after pulse only)) $\times 100$. A $0 \%$ PPI value indicates that there is no difference between the startle response (movement) to prepulse-plus-pulse trials and pulse alone trials. Positive values indicate the extent to which the startle response is diminished in the presence of a prepulse. Habituation was calculated according to the formula: \% habituation $=(1-($ startle amplitude at end of test session/startle amplitude at beginning of test session) $) \times 100$. A positive $\%$ habituation value indicates that a decrease in startle response has occurred over time.

\section{Drugs}

The following drugs were used: (-)-cannabidiol (Tocris), capsazepine (Sigma, Australia), clozapine (obtained from Dr Ben Capuano, Monash University), MK-801 (Sigma, Australia), Tween ${ }^{\circledR} 80$ (Sigma, Australia), Cremophor ${ }^{\mathbb{R}}$ EL (BASF), and ascorbic acid (David Craig Galenicals, Australia).

The injection volume in each mouse for each drug was $10 \mathrm{ml} / \mathrm{kg}$.

\section{Statistical Analysis}

A one-way ANOVA was used to compare both startle responses and \% habituation between treatment groups in Experiments 1 and 2. When a main effect of treatment was detected $(P<0.05)$, a Dunnett's $v s$ control post hoc test was used to determine the level of significance for each treatment group. Differences between both startle responses and \% habituation in Experiment 3 were measured using $2 \times 2 \times 2$ ANOVA between treatment groups. Four post hoc individual planned contrasts between drug treatment combinations of interest were carried out using $\alpha=0.0125$ $(\alpha=0.05 / 4)$.

A one-way repeated measures ANOVA was used to compare \% PPI between groups in Experiments 1 and 2 (MK-801 and cannabidiol dose-response curves) with four levels of the between-subjects factor $(0,0.1,0.3$, or $1 \mathrm{mg} / \mathrm{kg}$ MK-801 or $0,1,5$, or $15 \mathrm{mg} / \mathrm{kg}$ cannabidiol for Experiments 1 and 2 , respectively) and prepulse intensity (3, 6, or $12 \mathrm{~dB}(\mathrm{~A})$ above background) as the within-subjects factor. When a main effect of treatment on PPI was detected $(P<0.05)$, a Dunnett's vs control post hoc test was performed to evaluate significant differences.

A $2 \times 2 \times 2$ factorial ANOVA was used to compare \% PPI between groups in Experiment 3. There were three betweensubjects factors (capsazepine or vehicle, cannabidiol or vehicle, and MK- 801 or vehicle) and prepulse intensity $(3,6$, or $12 \mathrm{~dB}(\mathrm{~A})$ above background) was the within-subjects factor. When a main effect of treatment on PPI was detected $(P<0.05)$, four post hoc individual planned contrasts between drug treatment combinations of interest were carried out using $\alpha=0.0125$.

A $2 \times 2$ repeated measures ANOVA was used to compare $\%$ PPI between groups in Experiment 4 . There were two between-subjects factors (clozapine or vehicle and MK-801 or vehicle) and prepulse intensity $(3,6$, or $12 \mathrm{~dB}(\mathrm{~A})$ above background) was the within-subjects factor. Two post hoc individual planned contrasts were carried out using $\alpha=0.025(\alpha=0.05 / 2)$.

In all \% PPI data analyses, when a drug treatment $\times$ prepulse intensity interaction was detected, post hoc ANOVA was performed at each level of prepulse intensity.

Statistical analyses were performed with SPSS 11.5 for Windows (SPSS Inc.; Chicago, USA).

\section{RESULTS}

\section{Experiment 1: MK-801}

Statistical analysis revealed a significant effect on the startle response of VEH1 + VEH $2+$ MK 0.1 and VEH1 + VEH $2+$ MK 0.3 , but not VEH1 + VEH2 + MK 1 treatment, in comparison with vehicle $\left(\mathrm{F}_{3,23}=9.595, P<0.001, n=6-8\right.$, Figure 1a).

There was a significant main effect of MK-801 on PPI $\left(\mathrm{F}_{3,23}=8.044, P<0.01, n=6-8\right.$, Figure $\left.1 \mathrm{~b}\right)$. There was a significant effect of prepulse intensity, reflecting increased PPI in the presence of greater prepulse intensities $\left(\mathrm{F}_{2,46}=\right.$ $12.105, P<0.001, n=6-8)$. There was a significant treatment $\times$ prepulse intensity interaction $\left(\mathrm{F}_{6,46}=3.400\right.$, $P<0.01, n=6-8)$. Post hoc ANOVA was performed to analyse \% PPI data at each prepulse intensity, with Dunnett's test showing a significant effect at $12 \mathrm{~dB}$ for the $\mathrm{VEH} 1+\mathrm{VEH} 2+\mathrm{MK} 0.3$ treatment group $\left(\mathrm{F}_{3,23}=4.201\right.$, $P<0.05, n=6-8)$ and at 6 and $12 \mathrm{~dB}$ for the VEH1 + VEH $2+$ MK 1 treatment group $\left(\mathrm{F}_{3,23}=10.585, P<0.001, n=6-8\right)$.

There was no significant effect of MK-801 on habituation $(P>0.05$, ANOVA, Table 1$)$.
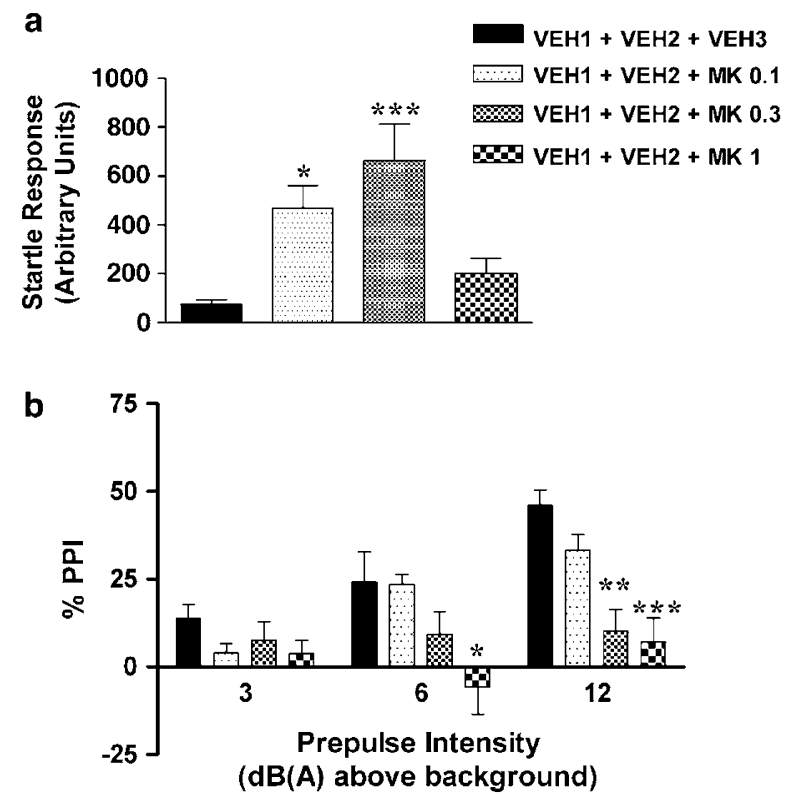

Figure I Effect of MK-80I (0. I, 0.3, or I mg/ $\mathrm{kg}$ ) following pretreatment with vehicles (VEHI, 40 min beforehand; $\mathrm{VEH} 2,20$ min beforehand) on (a) acoustic startle response and (b) prepulse inhibition (PPI) of the startle response in mice. Results are expressed as mean \pm SEM. $n=6-8$. $* P<0.05$, $* * P<0.01$, **** $P<0.00$ I vs vehicle treatment group (Dunnett's test). $M K=M K-80 I, V E H I=1: 1: 98$ Tween ${ }^{\circledR} 80: E t O H:$ saline, $V E H 2=1: 1: \mid 8$ Cremophor $^{\mathbb{R}} \mathrm{EL}: \mathrm{EtOH}$ : saline, $\mathrm{VEH} 3=0.1 \%$ ascorbic acid in distilled water. 
Table I Effect of Capsazepine $(20 \mathrm{mg} / \mathrm{kg}$ ) or Vehicle (VEHI) Administered $20 \mathrm{~min}$ Prior to Cannabidiol (I, 5, or I5 mg/kg) or Clozapine $(4 \mathrm{mg} / \mathrm{kg})$ or Vehicle $(\mathrm{VEH} 2)$, and $40 \mathrm{~min}$ Prior to $\mathrm{MK}-80 \mathrm{I}(0 . \mathrm{l}, 0.3$, or I mg/kg) or Vehicle (VEH3)

\begin{tabular}{lclr}
\hline Treatment & \% Habituation & Treatment & \% Habituation \\
\hline VEHI+VEH2+VEH3 & $-8.9+18.0$ & VEHI+CBD 5+MK I & $0.3 \pm$ I5.I \\
VEHI+VEH2+MK 0.I & $5.6 \pm 13.2$ & CPSZ 20+CBD 5+MK I & $10.6 \pm$ I3.5 \\
VEHI+VEH2+MK 0.3 & $-19.6 \pm 16.8$ & CPSZ 20+VEH2+MK I & $-27.5 \pm 18.9$ \\
VEHI+VEH2+MK I & $31.5 \pm 12.6$ & CPSZ 20+CBD 5+VEH3 & $36.6 \pm 15.2$ \\
VEHI+CBD I+VEH3 & $22.2 \pm 9.5$ & CPSZ 20+VEH2+VEH3 & $14.8 \pm 7.6$ \\
VEHI+CBD 5+VEH3 & $20.1 \pm 5.6$ & VEHI+CLOZ 4+VEH3 & $13.5 \pm 9.8$ \\
VEHI+CBD I5+VEH3 & $18.0 \pm 4.6$ & VEHI+CLOZ 4+MK I & $33.8 \pm 9.9$ \\
\hline
\end{tabular}

Data are presented as the mean $\left( \pm\right.$ SEM) \% habituation in mice. VEHI $=1: 1: 98$ Tween ${ }^{\circledR} 80:$ EtOH: saline, VEH2 $=1: 1: 18$ Cremophor ${ }^{\circledR}$ EL: EtOH: saline, $\mathrm{VEH} 3=0.1 \%$ ascorbic acid in distilled water.

These results indicate that MK-801 significantly increased the startle response at lower doses $(0.1$ and $0.3 \mathrm{mg} / \mathrm{kg})$. MK801 disrupted PPI at higher doses $(0.3$ and $1 \mathrm{mg} / \mathrm{kg})$ but did not affect habituation.

\section{Experiment 2: Cannabidiol}

There was a significant effect on startle response of $\mathrm{VEH} 1+\mathrm{CBD} 1+\mathrm{VEH} 3$ and VEH1 + CBD 15+VEH3, but not VEH1 + CBD 5 + VEH3 treatment, in comparison with vehicle $\left(\mathrm{F}_{3,21}=9.383, P<0.001, n=6-7\right.$, Figure $\left.2 \mathrm{a}\right)$.

There was no significant effect of cannabidiol $(1,5$, or $15 \mathrm{mg} / \mathrm{kg})$ on PPI $(P>0.05$, Figure $2 \mathrm{~b})$. There was a significant effect of prepulse intensity, reflecting increased PPI in the presence of greater prepulse intensities $\left(\mathrm{F}_{1.55,32.51}=78.887, P<0.001, n=6-7\right)$.

There was no significant effect of cannabidiol on habituation $(P>0.05$, ANOVA, Table 1$)$.

These results indicate that cannabidiol significantly increased the startle response at the lowest and highest dose administered ( 1 and $15 \mathrm{mg} / \mathrm{kg}$ ) but had no effect on PPI or habituation when administered with vehicle alone.

\section{Experiment 3: Capsazepine + Cannabidiol + MK-801}

There was a significant main effect of capsazepine on startle response $\left(\mathrm{F}_{1,42}=4.542, P<0.05, n=5-8\right)$ and a main effect of MK-801 on startle response $\left(\mathrm{F}_{1,42}=5.698, P<0.05, n=\right.$ $5-8$, Figure 3a). There was a significant interaction between the effects of capsazepine and cannabidiol on startle response $\left(\mathrm{F}_{1,42}=6.091, \quad P<0.05, \quad n=5-8\right)$. Individual planned comparisons did not reveal a significant effect of MK-801 on startle response compared with vehicle $(P>0.05, \mathrm{VEH} 1+\mathrm{VEH} 2+\mathrm{VEH} 3$ vs $\mathrm{VEH} 1+\mathrm{VEH} 2+\mathrm{MK}$ $1)$ nor any effect of cannabidiol or capsazepine on the startle response in MK-801-treated mice $(P>0.05$, CPSZ $20+$ $\mathrm{VEH} 2+\mathrm{MK} v s \mathrm{VEH} 1+\mathrm{VEH} 2+\mathrm{MK} 1$ and VEH1 + CBD $5+$ MK 1 vs VEH1 + VEH2 + MK 1).

There was a main effect of capsazepine $\left(\mathrm{F}_{1,42}=4.919\right.$, $P<0.05, n=5-8)$ and of MK-801 $\left(\mathrm{F}_{1,42}=8.832, P<0.01\right.$, $n=5-8$, Figure $3 \mathrm{~b})$ on PPI. There was a significant capsazepine $\times$ cannabidiol interaction $\left(\mathrm{F}_{1,42}=4.178, P<0.05\right.$, $n=5-8)$. There was a significant effect of prepulse intensity, reflecting increased PPI in the presence of greater prepulse intensities $\left(\mathrm{F}_{2,84}=38.071, P<0.001, n=5-8\right)$. There was
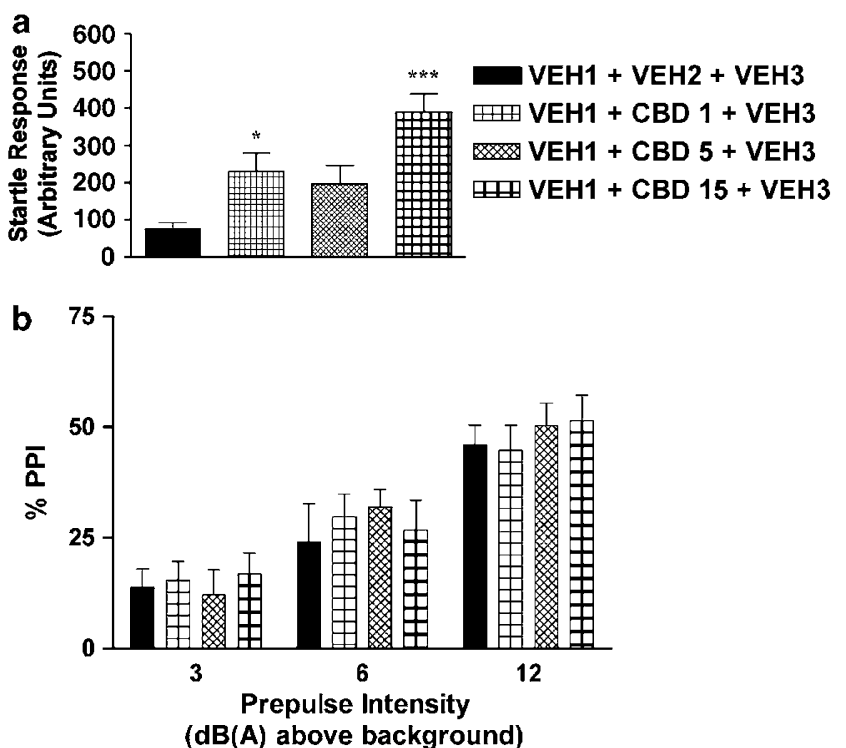

Figure 2 Effect of cannabidiol ( 1,5 , or $15 \mathrm{mg} / \mathrm{kg})$ following pretreatment with vehicle (VEHI, 20 min beforehand) and 20 min prior to a second vehicle treatment (VEH3) on (a) acoustic startle response and (b) prepulse inhibition (PPI) of the startle response in mice. Results are expressed as mean \pm SEM. $n=6-7$. $* P<0.05$, **** $P<0.00$ I vs vehicle treatment group (Dunnett's test). $C B D=$ cannabidiol, $V E H I=1: 1: 98$ Tween ${ }^{B}$ 80: EtOH: saline, VEH2 = 1: $1:$ : 8 Cremophor ${ }^{\circledR}$ EL: EtOH: saline, VEH3 = $0.1 \%$ ascorbic acid in distilled water.

also a significant prepulse intensity $\times$ MK- 801 interaction $\left(\mathrm{F}_{2,84}=7.723, P<0.01, n=5-8\right)$ and a significant prepulse intensity $\times$ capsazepine $\times$ cannabidiol $\times$ MK-801 interaction $\left(\mathrm{F}_{2,84}=5.393, P<0.01, n=5-8\right)$.

Owing to the interactions between prepulse intensity and drug treatment, \% PPI data were analysed by three-way ANOVA at each level of prepulse intensity. There was no significant effect of drug treatment at $3 \mathrm{~dB}$. At $6 \mathrm{~dB}$, there was a significant effect of MK-801 $\left(\mathrm{F}_{1,42}=16.088, P<0.001\right.$, $n=5-8)$ and a significant capsazepine $\times$ cannabidiol interaction $\left(\mathrm{F}_{1,42}=4.715, P<0.05, n=5-8\right)$. At $12 \mathrm{~dB}$, there were significant effects of capsazepine $\left(\mathrm{F}_{1,42}=6.147, P<0.05\right.$, $n=5-8)$ and MK-801 $\left(\mathrm{F}_{1,42}=8.507, P<0.01, n=5-8\right)$ and a significant capsazepine $\times$ cannabidiol interaction $\left(\mathrm{F}_{1,42}=\right.$ $5.150, P<0.05, n=5-8)$. At both $6 \mathrm{~dB}$ and $12 \mathrm{~dB}$, the 


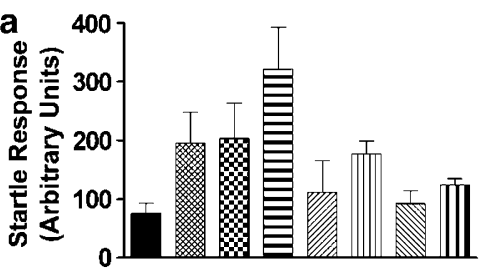

b

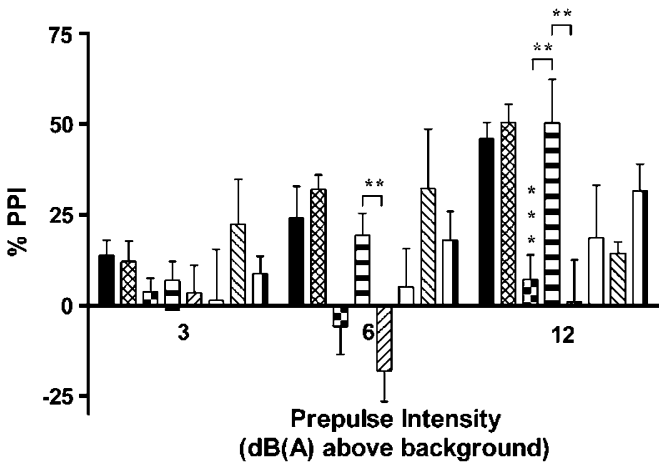

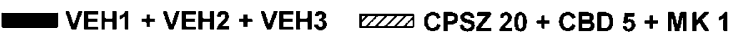

$\mathrm{VEH} 1+\mathrm{CBD} 5+\mathrm{VEH} 3 \mathrm{CPSZ} 20+\mathrm{VEH} 2+\mathrm{MK} 1$

$5 \mathrm{VEH} 1+\mathrm{VEH} 2+\mathrm{MK} 1 \mathrm{CPSZ} 20+\mathrm{CBD} 5+\mathrm{VEH} 3$

$\simeq \mathrm{VEH} 1+\mathrm{CBD} 5+\mathrm{MK} 1$ WW CPSZ $20+\mathrm{VEH} 2+\mathrm{VEH} 3$

Figure 3 Effect of pretreatment with capsazepine $(20 \mathrm{mg} / \mathrm{kg}) 20 \mathrm{~min}$ prior to cannabidiol $(5 \mathrm{mg} / \mathrm{kg})$ and $40 \mathrm{~min}$ prior to MK-80 I (I mg/ $\mathrm{kg}$ ) on (a) acoustic startle response and (b) prepulse inhibition (PPI) of the startle response in mice. Results are expressed as mean \pm SEM. $n=5-8$. $* * P<0.0$ l between treatment groups as indicated, $* * * P<0.00$ I vs vehicle treatment group (individual planned comparisons, $\alpha=0.0125$ ). CPSZ $=$ capsazepine, $\mathrm{CBD}=$ cannabidiol, $\mathrm{MK}=\mathrm{MK}-80 \mathrm{I}, \mathrm{VEHI}=1: \mathrm{l}: 98$ Tween ${ }^{\mathbb{R}}$ $80: \mathrm{EtOH}$ : saline, $\mathrm{VEH} 2=1:$ । : I 8 Cremophor $^{\mathrm{B}}$ EL: EtOH: saline, $\mathrm{VEH} 3=$ $0.1 \%$ ascorbic acid in distilled water

capsazepine $\times$ cannabidiol $\times$ MK-801 interaction approached significance $(P=0.067$ and $P=0.052$ respectively).

Individual planned comparisons between treatment groups at each level of prepulse intensity revealed significant differences in PPI between $\mathrm{VEH} 1+\mathrm{VEH} 2+$ VEH3 and VEH1 + VEH2 + MK 1 at the $12 \mathrm{~dB}$ prepulse level $\left(t_{0.0125,28}=4.689, P<0.001\right)$, between VEH1 + VEH $2+\mathrm{MK} 1$ and $\mathrm{VEH} 1+\mathrm{CBD} 5+\mathrm{MK} 1$ at the $12 \mathrm{~dB}$ level $\left(t_{0.0125,28}=3.111, P<0.01\right)$, and between VEH1 + CBD $5+$ MK 1 and CPSZ $20+$ CBD $5+$ MK 1 at the $6 \mathrm{~dB}\left(t_{0.0125,28}=\right.$ 3.623, $P<0.01)$ and $12 \mathrm{~dB}$ levels $\left(t_{0.0125,28}=2.946, P<0.01\right)$. There was no significant difference between CPSZ $20+$ $\mathrm{VEH} 2+\mathrm{MK} 1$ and VEH1 + VEH2 + MK 1 at any of the three prepulse intensities $(P>0.05)$.

There were no significant main effects of capsazepine, cannabidiol, or MK-801 on \% habituation $(P>0.05$, Table 1). There was a significant capsazepine $\times$ MK- 801 interaction $\left(\mathrm{F}_{1,42}=4.835, P<0.05, n=5-8\right.$, Table 1).

These results indicate that capsazepine, cannabidiol, and MK-801 administered with vehicle or in combination did not alter the startle response. The disruption in PPI induced by MK-801 $(1 \mathrm{mg} / \mathrm{kg})$ was significantly restored by cannabidiol $(5 \mathrm{mg} / \mathrm{kg})$ and this effect was reversed by pretreatment with capsazepine $(20 \mathrm{mg} / \mathrm{kg})$. Capsazepine alone did not reverse the MK-801-induced PPI disruption.
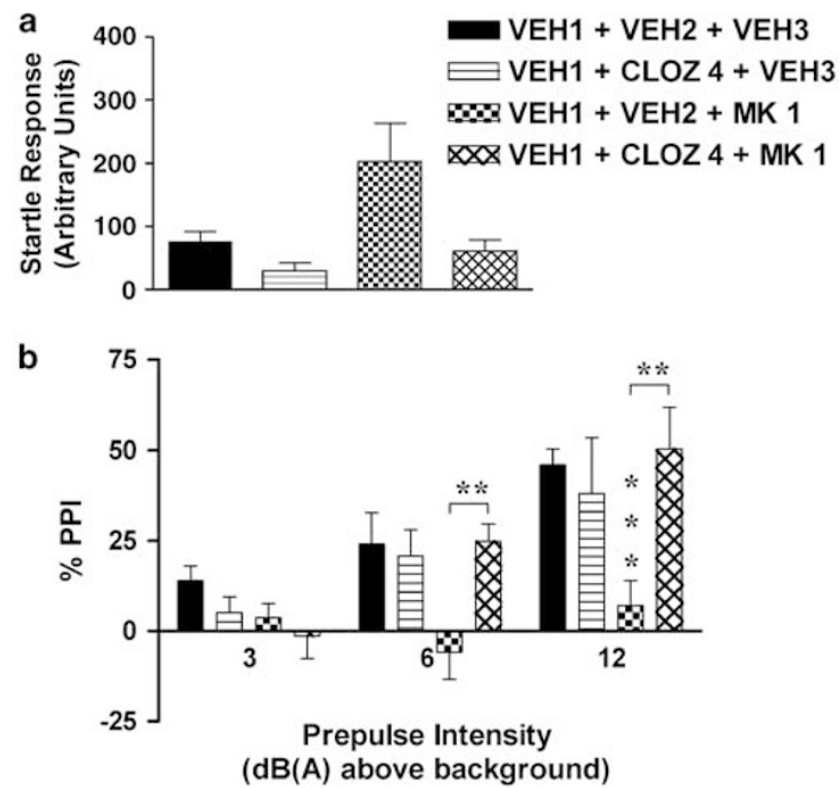

Figure 4 Effect of clozapine $(4 \mathrm{mg} / \mathrm{kg})$ following pretreatment with vehicle (VEHI, $20 \mathrm{~min}$ beforehand) and 20 min prior to MK-80 I (I mg/ $/ \mathrm{kg})$ on (a) acoustic startle response and (b) prepulse inhibition (PPI) of the startle response in mice. Results are expressed as mean \pm SEM $n=5-8$. ${ }^{*} * P<0.0$ l between treatment groups as indicated, $* * * P<0.00$ I vs vehicle treatment group (individual planned comparisons, $\alpha=0.0125$ ). $\mathrm{CLOZ}=$ clozapine, $\mathrm{MK}=\mathrm{MK}-80 \mathrm{I}, \mathrm{VEHI}=1: 1: 98$ Tween ${ }^{\mathbb{R}}$ 80: EtOH: saline, $\mathrm{VEH} 2=1: 1: 18 \mathrm{Cremophor}^{\mathbb{R}} \mathrm{EL}: \mathrm{EtOH}$ : saline, $\mathrm{VEH} 3=0.1 \%$ ascorbic acid in distilled water.

\section{Experiment 4: Clozapine + MK-801}

There was a main effect of clozapine on startle response $\left(\mathrm{F}_{1,22}=5.306, P<0.05, n=5-8\right.$, Figure $\left.4 \mathrm{a}\right)$. The effect of MK-801 on startle response approached significance $(P=0.069)$ but there was no significant clozapine $\times$ MK-801 interaction $(P>0.05)$. However, post hoc analysis revealed no significant difference in startle response between the VEH1 + VEH2 + VEH3 and either the VEH1 + CLOZ $4+\mathrm{VEH} 3$ or the VEH1 + CLOZ $4+$ MK 1 treatment groups.

There was a main effect of MK-801, but not clozapine, on PPI $\left(\mathrm{F}_{1,22}=5.034, P<0.05, n=5-8\right.$, Figure $\left.4 \mathrm{~b}\right)$. There was a significant clozapine $\times$ MK-801 interaction $\left(\mathrm{F}_{1,22}=8.305\right.$, $P<0.01, n=5-8)$. There was a significant effect of prepulse intensity, reflecting increased PPI in the presence of greater prepulse intensities $\left(F_{2,44}=20.566, P<0.001, n=5-8\right)$. There was also a significant prepulse intensity $\times$ clozapine interaction $\left(\mathrm{F}_{2,44}=3.883, P<0.05, n=5-8\right)$.

Post hoc three-way ANOVA was performed to analyse $\%$ PPI data at each level of prepulse intensity. At 6 and $12 \mathrm{~dB}$, there were significant clozapine $\times$ MK-801 interactions $\left(\mathrm{F}_{1,22}=4.803, P<0.05\right.$ and $\mathrm{F}_{1,22}=7.471, P<0.05$, respectively, $n=5-8)$. Individual planned comparisons at each level of prepulse intensity revealed significant differences in PPI between VEH1 + VEH2 + VEH3 and VEH1 + $\mathrm{VEH} 2+\mathrm{MK} 1$ at the $12 \mathrm{~dB}$ prepulse level $\left(t_{0.025,19}=4.689\right.$, $P<0.001)$ and between VEH1 + VEH2 + MK 1 and VEH1 + CLOZ $4+$ MK 1 at the $6 \mathrm{~dB}\left(t_{0.025,19}=3.335, P<0.01\right)$ and $12 \mathrm{~dB}$ levels $\left(t_{0.025,19}=3.275, P<0.01\right)$. 
There was a main effect of MK-801, but not clozapine, on habituation $\left(\mathrm{F}_{1,22}=6.156, P<0.05, n=5-8\right.$, Table 1$)$ but there was no significant clozapine $\times$ MK-801 interaction $(P>0.05)$. However, post hoc analysis revealed no significant difference in habituation between the VEH1 + VEH2 + VEH3 and either the VEH1 + VEH $2+$ MK 1 or the VEH1 + CLOZ $4+$ MK 1 treatment groups.

These results show that clozapine $(4 \mathrm{mg} / \mathrm{kg}$ ) decreased the startle response when administered with vehicle. This dose of clozapine did not disrupt PPI when administered with vehicle but did reverse the disruption in PPI induced by MK-801 (1 mg/kg).

\section{DISCUSSION}

The present results demonstrate that cannabidiol reverses MK-801-induced disruption of PPI. MK-801 dose-dependently disrupted PPI with a concomitant increase in the magnitude of the startle response at the lower and intermediate doses. Cannabidiol did not affect PPI when administered with vehicle alone, although it did increase the startle response. Cannabidiol reversed the disruption in PPI elicited by the highest dose of MK-801, an effect blocked by pretreatment with capsazepine prior to cannabidiol and MK-801. Clozapine also reversed the MK-801-induced disruption of PPI, while capsazepine alone did not. To our knowledge, this is the first report that cannabidiol can restore sensorimotor gating deficits induced by MK-801.

The disruption of PPI elicited by MK- 801 is consistent with previous reports of MK-801-induced disruption of PPI in mice (Curzon and Decker, 1998; Sakaue et al, 2003; Yee et al, 2004). It has been proposed that blockade of NMDA receptor-mediated transmission by noncompetitive antagonists such as MK-801 leads to excessive stimulation of non-NMDA glutamate-gated ion channels such as $\alpha$-amino3-hydroxy-5-methylisoxazole-4-propionic acid (AMPA) and kainic acid (KA) receptors via reduced stimulation of GABAergic interneurons and subsequent disinhibition of glutamatergic neurons (Deutsch et al, 2001). This effect may be manifest in schizophrenia as NMDA receptor hypofunction (NRH), leading not only to excitotoxic activation of AMPA/KA receptors but also to dysregulation of dopaminergic balance over the long term by diminishing cortical dopaminergic tone and thus increasing subcortical dopaminergic tone (Deutsch et al, 2001). However, modulation of dopaminergic activity is unlikely to be directly responsible for the disruptive effect of MK-801 on PPI, as MK-801 also disrupted PPI in wild-type and mutant $\mathrm{D}_{1}$ and $\mathrm{D}_{2}$ receptor knockout mice (Ralph-Williams et al, 2002), and typical antipsychotics with dopamine antagonist profiles do not restore MK-801-induced deficits in sensorimotor gating (Curzon and Decker, 1998; Martin et al, 2003). In the present study, the observation that the atypical antipsychotic clozapine restores MK-801-induced PPI disruption is in agreement with previous studies in rats and mice (Bakshi et al, 1994; Martin et al, 2003; Bubenikova et al, 2005) and provides a positive control for reversal of MK-801-induced sensorimotor gating deficits.

The startle response tended to be increased in some treatment groups such as the VEH1 + CBD $5+\mathrm{MK} 1$ group. The effects of centrally active drugs on startle response and
PPI in mice tend to be dissociated (Geyer et al, 2002), reflecting the relative simplicity of the neurocircuitry of the startle response and the more complex neural mechanisms regulating PPI. This dissociation is reflected in our data, in which a slightly increased startle response and disrupted PPI was observed in the VEH1 + VEH2 + MK 1 group while a similarly increased startle response and normal PPI was observed in the VEH1 + CBD $5+\mathrm{VEH} 3$ group.

The restorative effect of cannabidiol on MK-801-induced disruption reflects an antipsychotic potential of cannabidiol. This is in keeping with similar indications observed in rats in which cannabidiol reversed apomorphine-induced stereotypy (Zuardi et $a l, 1991$ ) and in a female schizophrenic patient in whom cannabidiol markedly reduced psychotic symptoms (Zuardi et al, 1995). The dose range of cannabidiol $(1,5$, and $15 \mathrm{mg} / \mathrm{kg})$ used in the present study is lower than doses previously determined to reverse the effects of psychoactive drugs in rats (Zuardi et al, 1991; Moreira and Guimaraes, 2005); however, it has previously been shown to be active in extinguishing conditioned place preference learning induced by amphetamine and cocaine (Parker et al, 2004). The lack of effect of either capsazepine or cannabidiol per se on PPI and startle response suggests that these drugs do not directly interfere with normal sensorimotor gating in the mouse. Importantly, the lack of effect of cannabidiol on startle reflects the comparative absence of sedative or cataleptic effects at these doses of cannabidiol.

There was no difference between the habituation observed in any of the treatment groups, suggesting that this form of startle response plasticity is not affected by TRPV1 or NMDA receptor antagonism or by cannabidiol in the present study. MK-801 has previously been reported to impair habituation in mice (Klamer et al, 2004). It has been suggested that separating habituation test sessions comprising consecutive startling pulses by a PPI session consisting of both startling pulses and prepulses may influence the degree of habituation (Varty et al, 2000). The present study used this experimental protocol which may explain the difference between the present results and the results of the Klamer et al study, which used a series of 121 consecutive pulse-alone trials.

In vitro studies have reported that cannabidiol has affinity for TRPV1 receptors and inhibits the hydrolysis and cellular uptake of the endogenous cannabinoid anandamide (Bisogno et al, 2001). Pretreatment with the TRPV1 receptor antagonist capsazepine prior to cannabidiol and MK-801 elicited a disruption of PPI similar to that observed with vehicle and MK-801 alone, suggesting that TRPV1 receptors may be involved in the restorative effect of cannabidiol on MK-801-induced disruption of PPI. However, although capsazepine has been shown to reverse capsaicin-induced effects such as dopaminergic cell death induced in vivo by intranigral injection (Kim et al, 2005) and to reverse antihyperalgesic effects of cannabidiol in rats (Costa et al, 2004), it has also been shown to block calcium channels and nicotinic cholinergic receptors at the same doses at which it blocks the TRPV1 receptor (Docherty et al, 1997; Liu and Simon, 1997), making it difficult to conclusively identify the involvement of TRPV1 receptors in the effect of cannabidiol in the present study. In preliminary experiments in our laboratory with systemic administration of the potent and 
selective TRPV1 antagonist iodoresiniferatoxin, hypomotility and accompanying hypothermia (unpublished observations) resulted in the startle response being too low for use in obtaining meaningful PPI data.

Following the detection of the expression of TRPV1 receptors in areas including the cortex, hippocampus, central amygdala, striatum, hypothalamus, substantia nigra, reticular formation and cerebellum (Mezey et al, 2000) and the localization of TRPV1 receptors on neurons, astrocytes, and pericytes (Toth et al, 2005), interest in the role of TRPV1 receptors has broadened from a focus on their role in pain perception into consideration of their involvement in the control of emotions, learning, and satiety. These brain regions are also part of the circuitry regulating sensorimotor gating (Koch and Schnitzler, 1997; Swerdlow and Geyer, 1998). From the observation that TRPV1 and tyrosine hydroxylase expression are colocalized in the substantia nigra, it was suggested that vanilloid-sensitive neurons are monoaminergic in this region (Mezey et al, 2000). Expression of TRPV1 receptors on glutamatergic terminals is also likely as their activation produces glutamate release in the rat hypothalamus (Sasamura et al, 1998), substantia nigra (Marinelli et al, 2003), and substantia gelatinosa (Yue et al, 2004). Further work has demonstrated that activation of TRPV1 receptors in the ventral tegmental area causes dopamine release in the nucleus accumbens, which may be due to increased glutamatergic transmission onto dopaminergic neurons (Marinelli et al, 2005). The existence of TRPV1 receptors in brain regions involved in sensorimotor gating is in agreement with the results obtained in the present study.

Anandamide has been proposed as an endogenous TRPV1 receptor agonist (Szallasi and Di Marzo, 2000). It activates TRPV1 receptors and facilitates neurotransmitter release (Zygmunt et al, 1999; Al-Hayani et al, 2001; Marinelli et al, 2003; for a review, see Ross, 2003). The efficacy of anandamide as a TRPV1 agonist varies with receptor reserve, cellular uptake, fatty acid amide hydrolase (FAAH) and lipoxygenase metabolism, and protein signalling pathways (Ross, 2003; Van Der Stelt and Di Marzo, 2004) and may be increased in pathological conditions such as inflammation in which upregulation of TRPV1 receptors occurs. An entourage effect of $\mathrm{N}$-acyl ethanolamides such as palmitoylethylamide coreleased with anandamide may facilitate the activity of anandamide at TRPV1 receptors (De Petrocellis et al, 2001; Smart et al, 2002). In the CNS, anandamide is present in brain regions expressing TRPV1 receptors including hippocampus and basal ganglia, regions also expressing high levels of $\mathrm{CB}_{1}$ receptor, for which anandamide is also an endogenous agonist.

Retrograde signalling of endocannabinoids involves postsynaptic synthesis and release following depolarization of the postsynaptic terminal and diffusion across the synaptic cleft to bind to presynaptic $\mathrm{CB}_{1}$ receptors (Wilson and Nicoll, 2001). As the effect of anandamide on both TRPV1 and $\mathrm{CB}_{1}$ receptors is regulated by FAAH hydrolysis and cellular uptake by the putative anandamide transporter (Hillard, 2000), it is possible that inhibition of anandamide hydrolysis and reuptake by cannabidiol could lead to potentiation of the activity of anandamide at both TRPV1 and $\mathrm{CB}_{1}$ receptors. Coexpression of $\mathrm{CB}_{1}$ and TRPV1 receptors has been demonstrated in rat dorsal root ganglion neurons (Ahluwalia et al, 2000; Bridges et al, 2003) and in rat mesencephalic cultures (Kim et al, 2005). Tonic activation of $\mathrm{CB}_{1}$ receptors exerts an inhibitory control over TRPV1 receptors, as anandamide or capsaicin-induced TRPV1 receptor-mediated effects are potentiated in the presence of a $\mathrm{CB}_{1}$ receptor antagonist (Maccarrone et al, 2000; Mang et al, 2001; Lever and Malcangio, 2002). Furthermore, cell death induced by capsaicin and the $\mathrm{CB}_{1}$ agonist HU-210 in rat mesencephalic culture was reversed by the $\mathrm{CB}_{1}$ receptor antagonist AM 251 and capsazepine, respectively, suggesting functional crosstalk between the two receptors (Kim et al, 2005). Cannabidiol produces TRPV1 activation at a nine-fold lower concentration than that at which it inhibits anandamide hydrolysis and at a seven-fold lower concentration than that at which it blocks cellular anandamide uptake (Bisogno et al, 2001), thus $\mathrm{CB}_{1}$ receptor-mediated effects resulting from inhibition of anandamide hydrolysis are likely to be counteracted by the direct activation of TRPV1 by cannabidiol. If cannabidiol exerted its effect on disrupted PPI in the present study via TRPV1 receptor activation, changes in mesolimbic glutamatergic and dopaminergic transmission may have occurred, thus counteracting the effect of NMDA receptor antagonism by MK- 801 .

The present results are of further interest in the context of the epidemiological relationship observed between cannabis consumption and schizophrenia. Individuals who consume cannabis are twice as likely to develop schizophrenia (Smit et al, 2004), although evidence does not suggest that cannabis consumption independently precipitates schizophrenia, but that it may be a companion to a complex group of factors predisposing an individual to the development of the disease (Arseneault et al, 2004). Thus although $\Delta^{9}$-THC and other psychotropic cannabinoids may be precipitating risk factors for schizophrenia, the present results provide scope for speculation on the potential role of the nonpsychotropic Cannabis constituent cannabidiol as an antipsychotic compound.

In summary, the present study is the first to investigate the effects of cannabidiol and capsazepine on PPI and suggests a promising avenue for investigation into the central effects of cannabidiol. The results indicate that cannabidiol reverses sensorimotor gating deficits induced by the NMDA receptor antagonist MK-801, and that this effect may be mediated by TRPV1 receptors as evidenced by the reversal of the effect of cannabidiol by capsazepine. Future studies using more selective ligands and several models of disrupted PPI will further elucidate the mechanism of the effects of cannabidiol on PPI.

\section{ACKNOWLEDGEMENTS}

We thank Dr Aidan Sudbury and Dr Bill Thiel (Monash University) for their invaluable assistance in statistical analysis of PPI data and $\mathrm{Dr}$ Ben Capuano (Monash University) for his synthesis and provision of clozapine.

\section{REFERENCES}

Ahluwalia J, Urban L, Capogna M, Bevan S, Nagy I (2000). Cannabinoid 1 receptors are expressed in nociceptive primary sensory neurons. Neuroscience 100: 685-688. 
Al-Hayani A, Wease KN, Ross RA, Pertwee RG, Davies SN (2001). The endogenous cannabinoid anandamide activates vanilloid receptors in the rat hippocampal slice. Neuropharmacology 41: 1000-1005.

Arseneault L, Cannon M, Witton J, Murray RM (2004). Causal association between cannabis and psychosis: examination of the evidence. Br J Psychiatry 184: 110-117.

Bakshi VP, Swerdlow NR, Geyer MA (1994). Clozapine antagonizes phencyclidine-induced deficits in sensorimotor gating of the startle response. J Pharmacol Exp Ther 271: 787-794.

Bisogno T, Hanus L, De Petrocellis L, Tchilibon S, Ponde DE, Brandi I et al (2001). Molecular targets for cannabidiol and its synthetic analogues: effect on vanilloid VR1 receptors and on the cellular uptake and enzymatic hydrolysis of anandamide. $\mathrm{Br} \mathrm{J}$ Pharmacol 134: 845-852.

Bolino F, Manna V, Di Cicco L, Di Michele V, Daneluzzo E, Rossi A et al (1992). Startle reflex habituation in functional psychoses: a controlled study. Neurosci Lett 145: 126-128.

Braff DL, Geyer MA (1990). Sensorimotor gating and schizophrenia. Human and animal model studies. Arch Gen Psychiatry 47: 181-188.

Bridges D, Rice ASC, Egertova M, Elphick MR, Winter J, Michael GJ (2003). Localisation of cannabinoid receptor 1 in rat dorsal root ganglion using in situ hybridisation and immunohistochemistry. Neuroscience 119: 803-812.

Bubenikova V, Votava M, Horacek J, Palenicek T, Dockery C (2005). The effect of zotepine, risperidone, clozapine and olanzapine on MK-801-disrupted sensorimotor gating. Pharmacol Biochem Behavior 80: 591-596.

Costa B, Giagnoni G, Franke C, Trovato AE, Colleoni M (2004). Vanilloid TRPV1 receptor mediates the antihyperalgesic effect of the nonpsychoactive cannabinoid, cannabidiol, in a rat model of acute inflammation. Br J Pharmacol 143: 247-250.

Curzon P, Decker MW (1998). Effects of phencyclidine (PCP) and (+)MK-801 on sensorimotor gating in CD-1 mice. Prog Neuropsychopharmacol Biol Psychiatry 22: 129-146.

De Petrocellis L, Davis JB, Di Marzo V (2001). Palmitoylethanolamide enhances anandamide stimulation of human vanilloid VR1 receptors. FEBS Lett 506: 253-256.

Deutsch SI, Rosse RB, Schwartz BL, Mastropaolo J (2001). A revised excitotoxic hypothesis of schizophrenia: therapeutic implications. Clin Neuropharmacol 24: 43-49.

Docherty RJ, Yeats JC, Piper AS (1997). Capsazepine block of voltage-activated calcium channels in adult rat dorsal root ganglion neurones in culture. Br J Pharmacol 121: 1461-1467.

French ED, Dillon K, Wu X (1997). Cannabinoids excite dopamine neurons in the ventral tegmentum and substantia nigra. Neuro Report 8: 649-652.

Geyer MA, Krebs-Thomson K, Braff DL, Swerdlow NR (2001). Pharmacological studies of prepulse inhibition models of sensorimotor gating deficits in schizophrenia: a decade in review. Psychopharmacology 156: 117-154.

Geyer MA, Mcllwain KL, Paylor R (2002). Mouse genetic models for prepulse inhibition: an early review. Mol Psychiatry 7: 1039-1053.

Geyer MA, Swerdlow NR, Mansbach RS, Braff DL (1990). Startle response models of sensorimotor gating and habituation deficits in schizophrenia. Brain Res Bull 25: 485-498.

Guimaraes VM, Zuardi AW, Del Bel EA, Guimaraes FS (2004). Cannabidiol increases Fos expression in the nucleus accumbens but not in the dorsal striatum. Life Sci 75: 633-638.

Hershkowitz M, Szechtman H (1979). Pre-treatment with delta 1tetrahydrocannabinol and psychoactive drugs: effects on uptake of biogenic amines and on behavior. Eur J Pharmacol 59: 267-276.

Hillard CJ (2000). Biochemistry and pharmacology of the endocannabinoids arachidonylethanolamide and 2-arachidonylglycerol. Prostaglandins Other Lipid Mediat 61: 3-18.
Hoffman HS, Ison JR (1980). Reflex modification in the domain of startle: I. Some empirical findings and their implications for how the nervous system processes sensory input. Psychol Rev 87: 175-189.

Howlett AC, Barth F, Bonner TI, Cabral G, Casellas P, Devane WA et al (2002). International Union of Pharmacology. XXVII. Classification of cannabinoid receptors. Pharmacol Rev 54: 161-202.

Karniol IG, Shirakawa I, Kasinski N, Pfeferman A, Carlini EA (1974). Cannabidiol interferes with the effects of delta 9tetrahydrocannabinol in man. Eur J Pharmacol 28: 172-177.

Kim SR, Lee da Y, Chung ES, Oh UT, Kim SU, Jin BK (2005). Transient receptor potential vanilloid subtype 1 mediates cell death of mesencephalic dopaminergic neurons in vivo and in vitro. J Neurosci 25: 662-671.

Klamer D, Palsson E, Revesz A, Engel JA, Svensson L (2004). Habituation of acoustic startle is disrupted by psychotomimetic drugs: differential dependence on dopaminergic and nitric oxide modulatory mechanisms. Psychopharmacology 176: 440-450.

Koch M, Schnitzler HU (1997). The acoustic startle response in rats - circuits mediating evocation, inhibition and potentiation. Behav Brain Res 89: 35-49.

Lever IJ, Malcangio M (2002). CB(1) receptor antagonist SR141716A increases capsaicin-evoked release of Substance P from the adult mouse spinal cord. Br J Pharmacol 135: 21-24.

Leweke FM, Schneider U, Radwan M, Schmidt E, Emrich HM (2000). Different effects of nabilone and cannabidiol on binocular depth inversion in man. Pharmacol Biochem Behavior 66: $175-181$.

Liu L, Simon SA (1997). Capsazepine, a vanilloid receptor antagonist, inhibits nicotinic acetylcholine receptors in rat trigeminal ganglia. Neurosci Lett 228: 29-32.

Maccarrone M, Lorenzon T, Bari M, Melino G, Finazzi-Agro A (2000). Anandamide induces apoptosis in human cells via vanilloid receptors. Evidence for a protective role of cannabinoid receptors. J Biol Chem 275: 31938-31945.

Mang CF, Erbelding D, Kilbinger H (2001). Differential effects of anandamide on acetylcholine release in the guinea-pig ileum mediated via vanilloid and non-CB1 cannabinoid receptors. $\mathrm{Br} J$ Pharmacol 134: 161-167.

Marinelli S, Di Marzo V, Berretta N, Matias I, Maccarrone M, Bernardi G et al (2003). Presynaptic facilitation of glutamatergic synapses to dopaminergic neurons of the rat substantia nigra by endogenous stimulation of vanilloid receptors. J Neurosci 23: 3136-3144.

Marinelli S, Pascucci T, Bernardi G, Puglisi-Allegra S, Mercuri NB (2005). Activation of TRPV1 in the VTA excites dopaminergic neurons and increases chemical- and noxious-induced dopamine release in the nucleus accumbens. Neuropsychopharmacology 30: 864-870.

Martin RS, Secchi RL, Sung E, Lemaire M, Bonhaus DW, Hedley LR et al (2003). Effects of cannabinoid receptor ligands on psychosis-relevant behavior models in the rat. Psychopharmacology 165: 128-135.

McQueen DS, Bond SM, Smith PJ, Balali-Mood K, Smart D (2004). Cannabidiol lacks the vanilloid VR1-mediated vasorespiratory effects of capsaicin and anandamide in anaesthetised rats. Eur J Pharmacol 491: 181-189.

Mezey E, Toth ZE, Cortright DN, Arzubi MK, Krause JE, Elde R et al (2000). Distribution of mRNA for vanilloid receptor subtype 1 (VR1), and VR1-like immunoreactivity, in the central nervous system of the rat and human. Proc Natl Acad Sci USA 97: 3655-3660.

Moreira FA, Guimaraes FS (2005). Cannabidiol inhibits the hyperlocomotion induced by psychotomimetic drugs in mice. Eur J Pharmacol 512: 199-205.

Parker LA, Burton P, Sorge RE, Yakiwchuk C, Mechoulam R (2004). Effect of low doses of delta9-tetrahydrocannabinol and 
cannabidiol on the extinction of cocaine-induced and amphetamine-induced conditioned place preference learning in rats. Psychopharmacology 175: 360-366.

Rakhshan F, Day TA, Blakely RD, Barker EL (2000). Carriermediated uptake of the endogenous cannabinoid anandamide in RBL-2H3 cells. J Pharmacol Exp Ther 292: 960-967.

Ralph-Williams RJ, Lehmann-Masten V, Otero-Corchon V, Low MJ, Geyer MA (2002). Differential effects of direct and indirect dopamine agonists on prepulse inhibition: a study in D1 and D2 receptor knock-out mice. J Neurosci 22: 9604-9611.

Ross RA (2003). Anandamide and vanilloid TRPV1 receptors. $\mathrm{Br} J$ Pharmacol 140: 790-801.

Sakaue M, Ago Y, Baba A, Matsuda T (2003). The 5-HT1A receptor agonist MKC-242 reverses isolation rearing-induced deficits of prepulse inhibition in mice. Psychopharmacology 170: 73-79.

Sasamura T, Sasaki M, Tohda C, Kuraishi Y (1998). Existence of capsaicin-sensitive glutamatergic terminals in rat hypothalamus. Neuro Report 9: 2045-2048.

Smart D, Jonsson KO, Vandevoorde S, Lambert DM, Fowler CJ (2002). 'Entourage' effects of $\mathrm{N}$-acyl ethanolamines at human vanilloid receptors. Comparison of effects upon anandamideinduced vanilloid receptor activation and upon anandamide metabolism. Br J Pharmacol 136: 452-458.

Smit F, Bolier L, Cuijpers P (2004). Cannabis use and the risk of later schizophrenia: a review. Addiction 99: 425-430.

Swerdlow NR, Geyer MA (1998). Using an animal model of deficient sensorimotor gating to study the pathophysiology and new treatments of schizophrenia. Schizophr Bull 24: 285-301.

Szallasi A, Di Marzo V (2000). New perspectives on enigmatic vanilloid receptors. Trends Neurosci 23: 491-497.

Toth A, Boczan J, Kedei N, Lizanecz E, Bagi Z, Papp Z et al (2005). Expression and distribution of vanilloid receptor 1 (TRPV1) in the adult rat brain. Brain Res Mol Brain Res 135: 162-168.
Van Der Stelt M, Di Marzo V (2004). Endovanilloids. putative endogenous ligands of transient receptor potential vanilloid 1 channels. Eur J Biochem 271: 1827-1834.

Varty GB, Paulus MP, Braff DL, Geyer MA (2000). Environmental enrichment and isolation rearing in the rat: effects on locomotor behavior and startle response plasticity. Biol Psychiatry 47: 864-873.

Watanabe K, Kayano Y, Matsunaga T, Yamamoto I, Yoshimura H (1996). Inhibition of anandamide amidase activity in mouse brain microsomes by cannabinoids. Biol Pharm Bull 19: 1109-1111.

Wilson RI, Nicoll RA (2001). Endogenous cannabinoids mediate retrograde signalling at hippocampal synapses. Nature 410: 588-592.

Yee BK, Chang DT, Feldon J (2004). The effects of dizocilpine and phencyclidine on prepulse inhibition of the acoustic startle reflex and on prepulse-elicited reactivity in C57BL6 mice. Neuropsychopharmacology 29: 1865-1877.

Yue HY, Fujita T, Kawasaki Y, Kumamoto E (2004). AM404 enhances the spontaneous release of L-glutamate in a manner sensitive to capsazepine in adult rat substantia gelatinosa neurones. Brain Res 1018: 283-287.

Zuardi AW, Morais SL, Guimaraes FS, Mechoulam R (1995). Antipsychotic effect of cannabidiol. J Clin Psychiatry 56: 485-486.

Zuardi AW, Rodrigues JA, Cunha JM (1991). Effects of cannabidiol in animal models predictive of antipsychotic activity. Psychopharmacology 104: 260-264.

Zuardi AW, Shirakawa I, Finkelfarb E, Karniol IG (1982). Action of cannabidiol on the anxiety and other effects produced by delta 9-THC in normal subjects. Psychopharmacology 76: 245-250.

Zygmunt PM, Petersson J, Andersson DA, Chuang H, Sorgard M, Di Marzo V et al (1999). Vanilloid receptors on sensory nerves mediate the vasodilator action of anandamide. Nature 400: 452-457. 